\title{
Pencarian Tempat Wisata Di Kota Bitung Dengan Panduan Mobil Aplikasi
}

\author{
Reynoldus Andrias Sahulata*1, Rehka Bellavita Kawang ${ }^{2}$, Delisbet Fitri Sarinda ${ }^{3}$ \\ ${ }^{1,2,3}$ Sistem Informasi, Fakultas Ilmu Komputer, Universitas Klabat \\ E-mail: * ${ }^{1}$ rey_sahulata@unklab.ac.id, ${ }^{2} 11310410 @$ student.unklab.ac.id, \\ ${ }^{3}$ s11510139@student.unklab.ac.id
}

\begin{abstract}
Abstrak
Kota Bitung yang merupakan salah satu kota administratif di provinsi Sulawesi Utara, memiliki potensi wisata baik wisata alam, wisata religi, wista sejarah, wisata kuliner dan wisata industri. Potensi ini belum optimal di kelola oleh pemerintah administratif kota Bitung untuk meningkatkan pendapatan asli daerah, hal ini disebabkan karena potensi yang ada di kota Bitung tidak sepenuhnya diketahui oleh wisatwan dalam negeri maupun wisatawan mancanegara ditambah dengan pandemic COVID-19. Penelitaian ini bertujuan memperkenalkan tempat wisata potensial di kota bitung sehingga dengan berakhirnya pandemi, maka perkunjungan ketempat wisata di kota Bitung dapat berkelanjutan. Dengan membangun sistem aplikasi informasi tempat tujuan wisata di kota Bitung menggunakan platform sistem operasi android, flutter sebagai framework, android studio, visual studio code, java, dart programing, untuk membangun sistem aplikasi ini, maka dihasilkan sebuah aplikasi yang diadaptasikan pada smartphone berbasis android. Dengan adanya aplikasi pencarian tempat wisata di Kota Bitung yang tersedia dalam bentuk MobApp menjadi alternatif dalam pemberian informasi tempat wisata potensian di Kota Bitung, oleh sebab itu perlu adanya tambahan fituru pendukung dalam memberikan rating pada setiap objek tempat wisata dan diperlukan tambahan objek yang belum di rilis oleh Kemenparekraf/Baparekraf serta perluan penggunaan aplikasi dengan dapat dijalankan pada IOS.
\end{abstract}

Kata kunci-Aplikasi wisata kota bitung, flutter, java

\begin{abstract}
Bitung City, which is one of the administrative cities in North Sulawesi province, has tourism potential both natural tourism, religious tourism, historical tourism, culinary tourism and industrial tourism. This potential has not been optimally managed by the administrative government of the city of Bitung to increase regional revenue, this is because the potential in the city of Bitung is not fully known by domestic tourists and foreign tourist coupled with the COVID-19 pandemic. The methodology used applied using a spiral method to build an information application system for tourist destinations in the city of Bitung, using the Android operating system platform, flutter as a framework, android studio, visual studio code, java, dart programing, to build this application system, it produced an application that was adapted to an Android-based smartphone which provides information on tourism potential in the city of Bitung. The search application for tourist attractions in Bitung City which is available in the form of a MobApp, it becomes an alternative in providing information on potential tourist attractions in Bitung City, therefore there is a need for additional supporting features in rating each tourist attraction and additional objects that have not been released by Kemenparekraf/Baparekraf and the need to use applications that can run on IOS.
\end{abstract}

Keywords - Bitung city tourism application, flutter, java 


\section{PENDAHULUAN}

Indonesia negara yang memiliki keindahan alam yang beraneka bentuk, yang merupakan potensi yang tidak akan habis untuk dapat diexploitasi [1]. Potensi tersebut mengalami gangguan dalam mendatangkan wisatawa baik wisatawan domestik apa lagi wisatawan manca negara dengan adanya wabah pandemi COVID-19, dimana oleh WHO ditetapkan sebagai pandemi global pada tanggal 11 maret 2020, dimana semua sektor terkena dampak dari pandemi ini [2]. Hal ini amat terasa pada dunia industri pariwisata dengan timbulnya dilema pada semua sektor terkait lainnya yang hidup disekitaran industri pariwisata [3]. Dengan melihat potensi yang dimiliki Indonesia pada sektor pariwisata serta adanya pandemi yang sampai bulan Agustus 2021 ini masih terjadi, maka penelitian ini dilakukan dengan harapan pada satu saat dunia bisa menyelesaikan masalah pandemi COVID-19, maka bersamaan dengan itu industri pariwisata dapat bangkit kembali lagi dari keterpurukan yang terjadi, maka penelitian yang dilakukan adalah mempersiapkan sarana yang sudah bisa dilakukan sekarang ini dengan membuat aplikasi yang diimplementasikan pada smartphone berbasis Android yang menyediakan informasi potensi pariwisata yang dimiliki kota Bitung di Sulawesi Utara [4]. Potensi Kota Bitung dalam bidang wisata tidak diragukan karna sejumlah tempat yang ada di Kota Bitung memiliki daya tarik tersendiri dibandingkan dengan destinasi wisata yang ada di tanah air. Wisata adalah kegiatan perjalanan yang dilakukan oleh seseorang atau sekelompok orang dengan mengunjungi tempat tertentu untuk tujuan rekreasi, pengembangan pribadi, atau mempelajari keunikan daya tarik wisata yang dikunjungi, dalam jangka waktu sementara. Wisata memiliki banyak ragam, macam dan jenis, mulai dari wisata alam, religi, bahari, budaya, buru, domestik, karya, kesehatan, nusantara, puri atau semacam istana, hingga tirta atau yang berhubungan dengan air [5]. Dengan tersedianya informasi yang dapat diakses pada media bergerak, dapat memberikan informasi secara virtual kepada pada pelancong didalam negri ataupun oleh para wisatawan manca negara, pada saat pandemi sekarang ini dan setelah new normal dapat menghantarkan pada pelancong ke tempat yang nyata [6]. Untuk lebih memudahkan dalam penggunaan pencarian tempat wisata pada aplikasi tersedia layanan dalam bentuk video dari objek yang dipilih serta pengguna dapat menjadikan titik awal dimana posisi awal pengguna menggunakan aplikasi dan pencarian terhadap objek wisata yang dituju, sehingga pencapaian tempat wisata dapat diketahui dengan pasti terutama bagi pengguna yang tidak memiliki pengalaman pada wilayah Kota Bitung.

\section{METODE PENELITIAN}

Metodologi penelitian yang dipakai untuk membuat Aplikasi pencarian tempat wisata di kota Bitung dengan panduan mobil aplikasi [7], yaitu dengan menerapkan metode rekayasa perangkat lunak melalui semua aspek produksi perangkat lunak, mulai dari mendefinisikan kebutuhan pengguna, merancang aplikasi sesuai kebutuhan pengguna, tahap pengkodean dan tahap pengujian aplikasi serta peneliti menggunakan instrument observasi dan wawancara.

\subsection{Instrumentasi}

Pada bagian ini menjelaskan bagaimana cara menjalankan untuk menyelesaikan penelitian dalam mengumpulkan data yang memungkinkan peneliti dapat dilakukan, dimana teknik yang digunakan pada penelitan ini melibatkan beberapa sumber data yaitu dengan menggunakan data primer dan pada data sekunder, dimana dapat dijelaskan sebagai berikut : 


\subsubsection{Observasi}

Metode observasi dilakukan dengan melakukan pengamatan di kota Bitung dimana materi yang digunakan sebagai bagian informasi yang disajikan dalam aplikai berupa semua objek yang dapat mewakili sebagai icon yang mewakili potensi kota Bitung.

\subsubsection{Study Literatur}

Metode ini dilakukan dengan mencari penelitian-penelitian yang terkait untuk membantu dalam proses, yang bertujuan untuk mempelajari cara kerja sisitem, dari sistem sebelumnya agar dapat membantu dalam proses pembuatan penelitian ini.

\subsection{Teknik Pengumpulan Data}

1. Peneliti melakukan observasi langsung dilapangan untuk mendapatkan data yang diperlukan.

2. Peneliti juga melakukan studi pustaka terhadap literatur-literatur terkait serta jurnal-jurnal yang mendukung akan penelitian ini.

3. Peneliti melakukan tatap muka langsung dengan pelaku sektor industri pariwisata baik dipemerintahan ataupun masyarakat industry pariwisata.

\subsection{Analisis Sistem}

Pada tahap ini analisis, peneliti menggunakan model perancangan UML. Dalam permodelan aplikasi ini, menggunakan 4 model diagram yaitu, use case diagram dan class diagram, yang dapat menjelaskan semua proses yang terjadi pada aplikasi, dimana untuk menjelaskan penggunaan metode yang diterapakan pada rekayasa perangkat lunak dengan menggunakan model spiral, dimana Metode ini menerapkan dalam pembuatan aplikasi agar menjadi lebih efisien dan berkualitas, disebabkan Model ini melakukan semua tahapn secara tuntas dan dapat melakukan perbaikan sampai selesai. Model Waterfall [8] terlihat pada gamabar 1 .

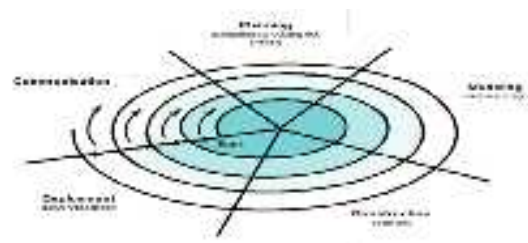

Gambar 1. model spiral.

\subsubsection{Use Case Diagram}

Pada use case diagram dijelaskan mengenai hubungan antara pengguna dengan fungsifungsi yang ada di dalam aplikasi [9]. Disini peneliti menggambarkan interaksi antara pengguna dengan aplikasi yang terjadi dengan menggunakan use case diagram. 


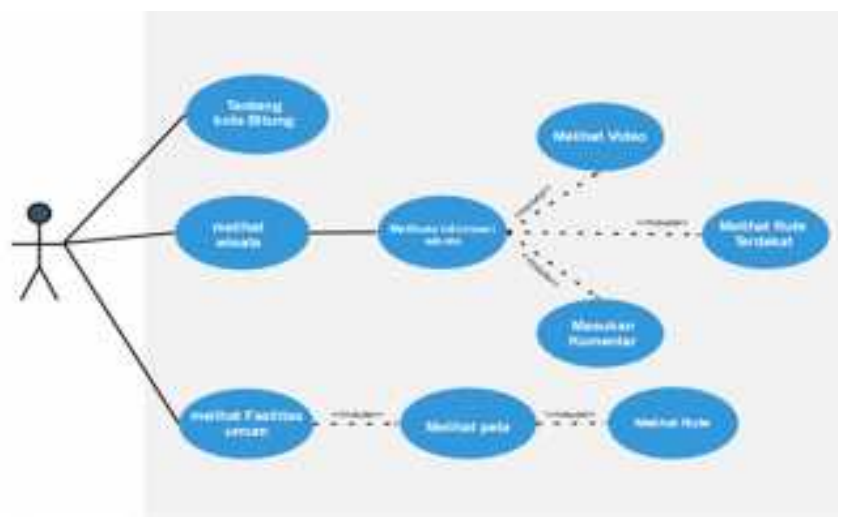

Gambar 2. Use Case Diagram Aplikasi

Pada gambar 2., menjelaskan cara kerja sitem aplikasi yang dibangun, dimana pengguna dapat memilih mengakses semua fitur yang menjelaskan keberadaan potensi pariwisata kota Bitung secara lengkap.

\subsubsection{Class Diagram}

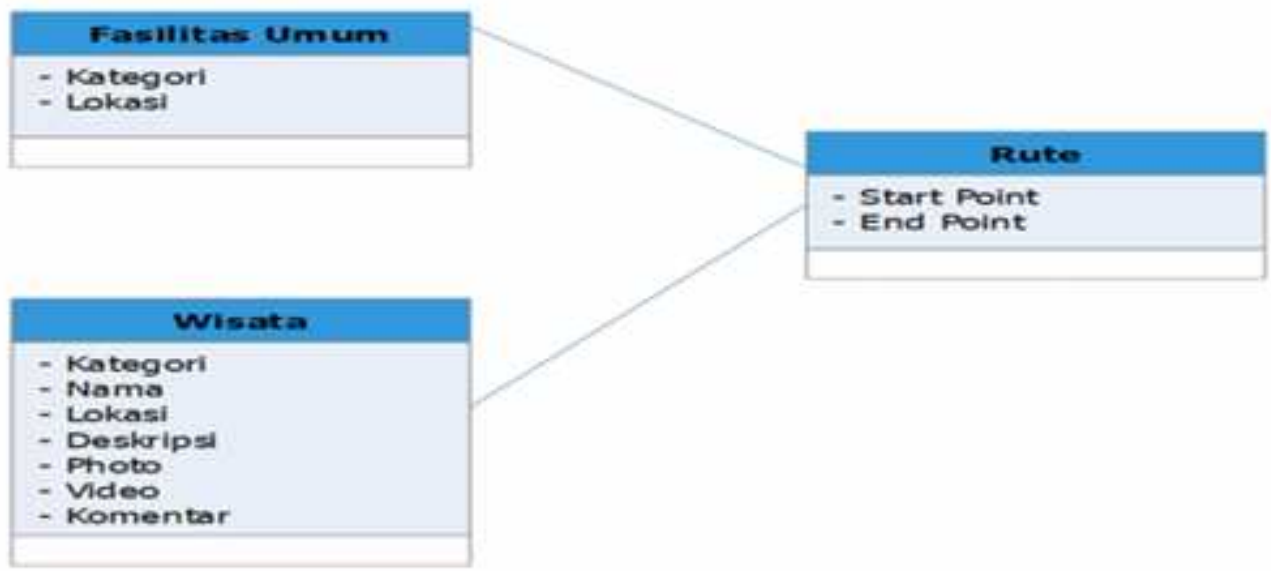

Gambar 3. Perancangan Class Diagram Aplikasi

Pada Gambar 3. Class diagram menggambarkan bagaimana interaksi hubungan antar class yang membangun aplikasi yang dihasilkan [10].

Pada kelas ini menampilkan informasi tentang objek wisata yang ada pada kota Bitung, fasilitas yang ditawarkan serta dilengkapi dengan ture pejalanan menuju tempat tersebut dan adanya fasilitas umum yang diperlukan masyarakat. 


\subsubsection{Sequence Diagram}

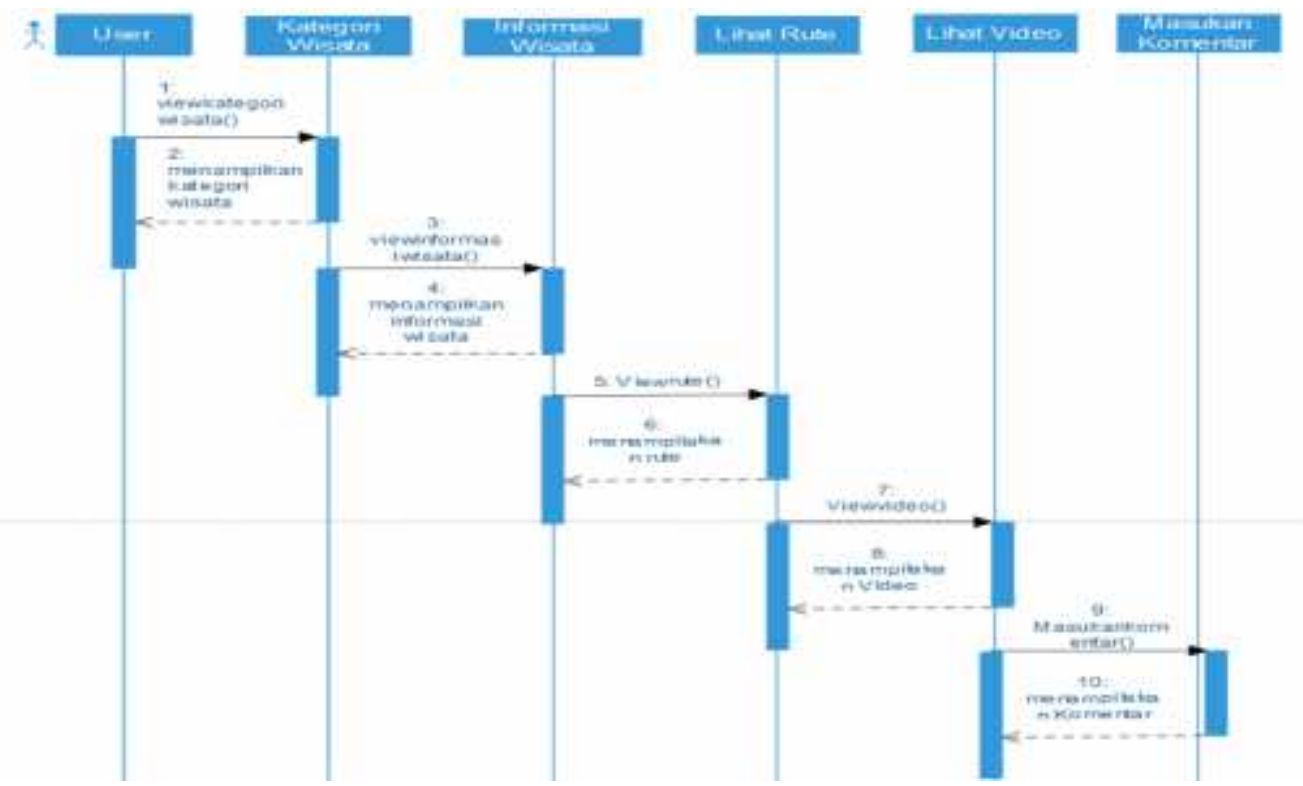

Gambar 4. Sequence Diagram Wisata

Gambar 4. Sequence Diagram menggambarkan proses kerja secara berurutan mengenai alur kerja antara proses sehingga mendapatkan feedback sesuai dengan interaksi yang digambarkan dalam use case diagram.

\subsubsection{Activity diagram}

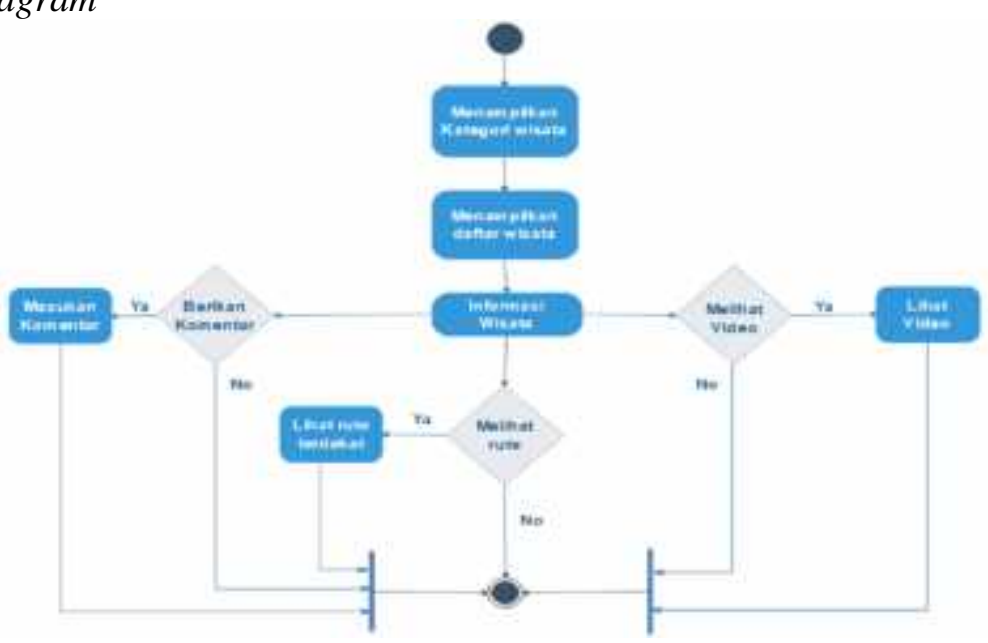

Gambar 5. Activity diagram pengguna untuk kategori wisata

Vol. 10, No. 2, Oktober 2021 


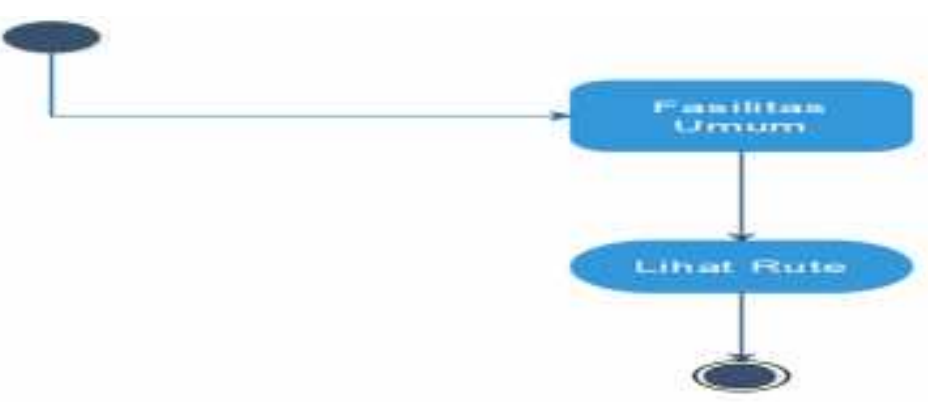

Gambar 6 Activity diagram pengguna untuk fitur tambahan

Gambar 5 dan 6 merupakan gambar Activity diagram yangmenggambarkan berbagai alur aktifitas dalam aplikasi yang dihasilkan disaat perancangan.

\section{HASIL DAN PEMBAHASAN}

Pada Gambar 7 digambarkan bagaimana konseptual aplikasi yang ada pada sistem ini.

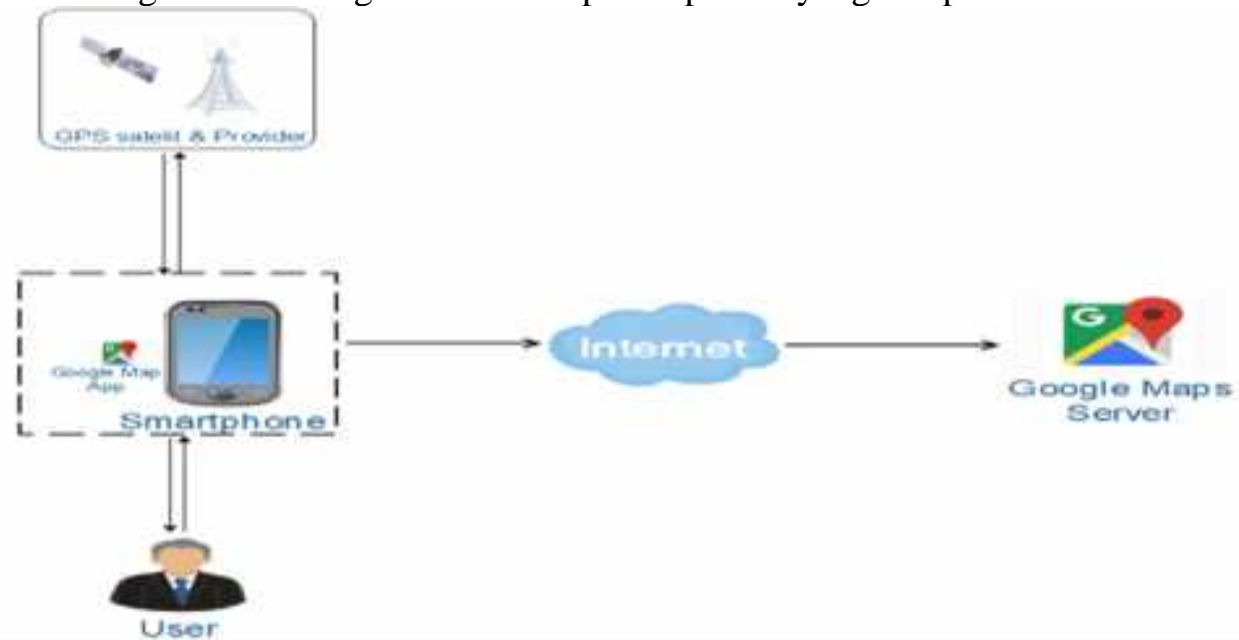

Gambar 7. Garis besar kerangka konseptual aplikasi

Penjelasan gambar 7. adalah sebagai berikut :

1. Pengguna aplikasi menggunakan smartphone berbasi Android yang telah terinstal aplikasi yang terhubung internet.

2. Aplikasi terhubung ke Google Maps untuk mendapatkan informasi terkini mengenai tempat wisata.

3. Untuk menampilkan start point dan end point pada rute perjalanan, maka aplikasi akan menggunakan GPS pada smartphone yang akan terhubung ke GPS satelit kemudian GPS satelit mengirim start point dan end point yang akan ditampilkan pada google map.

3.1 Tampilan Sistem Aplikasi pencarian tempat wisata di kota Bitung dengan panduan mobapp

Vol. 10, No. 2, Oktober 2021 
Pada bagian ini merupakan penjelasan dari sistem aplikasi yang dibangun untuk menjelaskan mengenai implementasi dari aplikasi pencarian tempat wisata di kota Bitung dengan panduan mobapp.

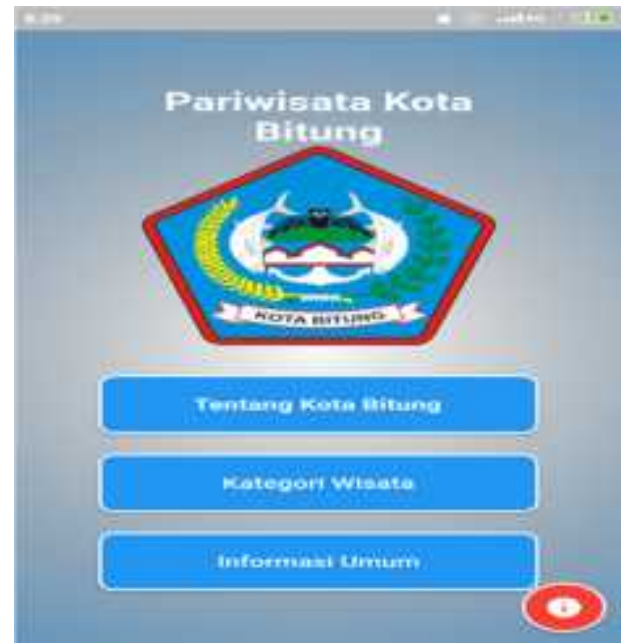

Gambar 8. Menu Utama

Gambar 9. merupakan interface menu utama pada aplikasi pencarian tempat wisata di kota Bitung dengan panduan mobapp. Pada frame menu utama terdapat menu Tentang Kota Bitung, Kategori Wisata dan Informasi Umum untuk membantu pengguna aplikasi.

Pada Menu Utama tersebut akan menghantarkan pengguna menekan tombol untuk mengenal kota Bitung lebih lanjut, terlihat pada gambar 9. Selayang pandang kota Bitung.

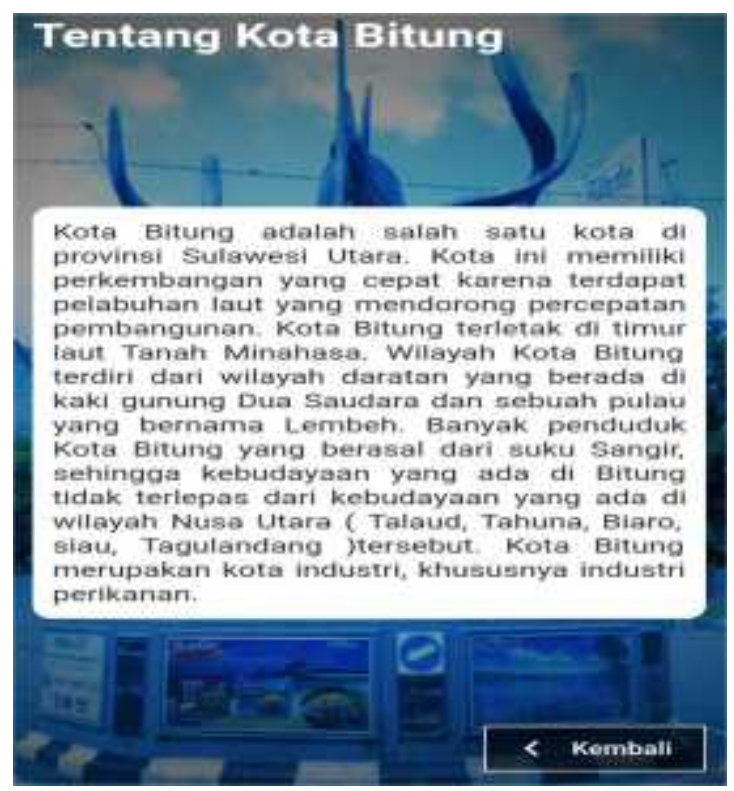

Gambar 9. Selayang pandang Kota Bitung 


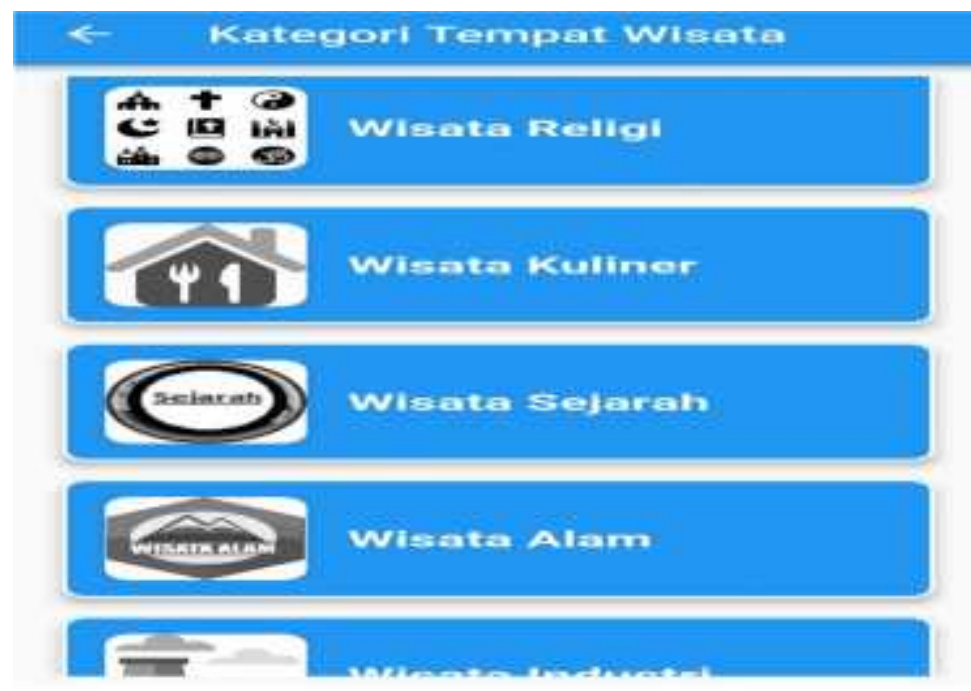

Gambar 10. Daftar Kategori Tempat Wisata

Gambar 10. Adalah nafigasi untuk dapat memilih daftar kategori tempat wisata dimana pengguna telah menekan button kategori wisata pada menu utama aplikasi.

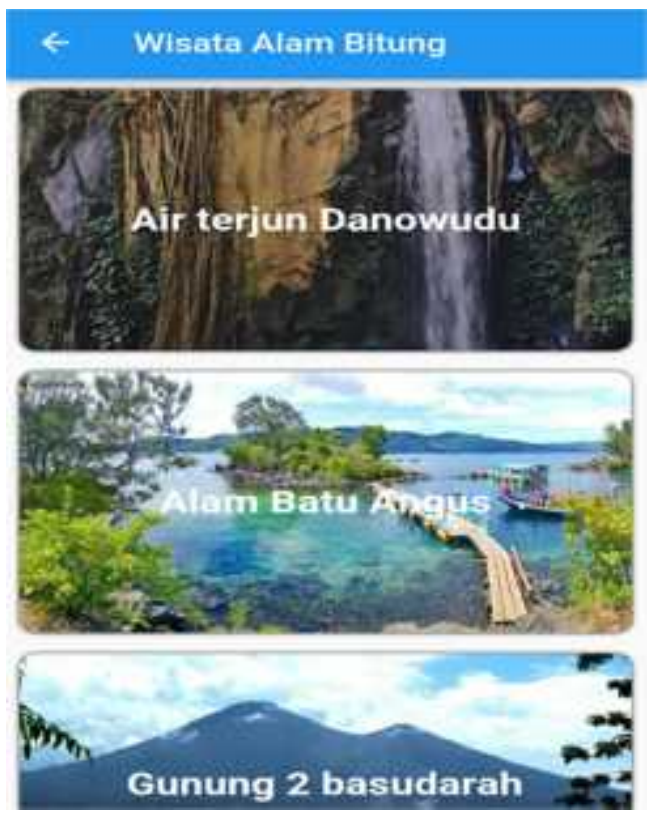

Gambar 11. Wisata Alam Bitung

Dimana pada Gambar 11 ini menunjukan objek wisata yang menjadi icon yang dapat dikunjungi setelah pandemi berakhir, atau tempat wisata yang menjadi destinasi yang merupakan pesona yang dimiliki kota Bitung. 


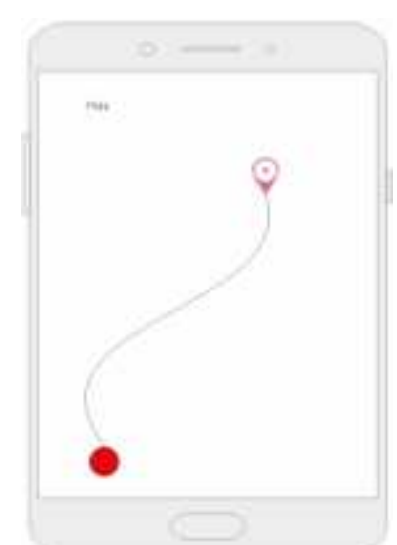

Gambar 12. Titik awal ke titik akhir tempat wisata yang dituju

Pada aplikasi ini dilengkapi penggunaan Google Maps pada saat pengguna mencari tempat tujuan lokasi sebagai titik akhir pada pencarian dan sebagai titik awal dari pencariana adalah posisi pengguna tak kala pengguna mengaktifkan aplikasi sebagai mana yang terlihat pada gambar 12.

\section{KESIMPULAN}

Hasil dari penelitian ini berupa informasi yang dapat digunakan pada masa pandemi utnuk melakukan tour secara visual pada tempat-tempat tujuan wisata di Kota Bitung, yang dilengkapi dengan informasi penunjang lainya yang diperlukan pelancong pada saat melakukan perkunjungan wisata di Kota Bitung, sehingga perkunjungan yang dilakukan dapat berlangsung lebih menyenangkan disebabkan adanya informasi pendukung yang tersedia pada aplikasi.

\section{SARAN}

Hasil dari penelitian dapat ditingkatkan tersedianya layanan yang dapat menyimpan informasi yang telah dilihat ke dalam media penyimpan external, sehingga jika aplikasi terputus dengan internet, maka informasi objek wisata yang pernah dilihat dapat digunakan.

\section{UCAPAN TERIMA KASIH}

Peneliti mengucapkan terima kasih kepada Bapak Adelien Manoy dan Bapak Vrasir Pansing,, dalam menyandang dana, sehingga penelitan ini dapat berlangsung sesuai harapan.

\section{DAFTAR PUSTAKA}

[1] Arum Sutrisni Putri, 2020, Jenis-jenis Keberagaman di Indonesia, https://www.kompas.com/skola/read/2020/01/21/090000869/jenis-jenis-keberagaman-diindonesia?page=all, diakses $\operatorname{tgl} 21 / 01 / 2021$.

[2] Ahmad Naufal Dzulfaroh , 2021, Hari Ini dalam Sejarah: WHO Tetapkan Covid-19 sebagai Pandemi Global, https://www.kompas.com/tren/read/2021/03/11/104000165/hariini-dalam-sejarah--who-tetapkan-covid-19-sebagai-pandemi-global?page=all, diakses tgl $11 / 03 / 2021$. 
[3] Veta Lidya Delimah Pasaribu, 2021, Pandemik Covid-19 MenjadiI Dilema Bagi Sektor Pariwisata Di Indonesia, http://ppm.unpam.ac.id/2021/01/01/pandemik-covid-19-menjadidilema-bagi-sektor-pariwisata-di-indonesia/, diakses tgl 30/03/2021.

[4] J.-J. P. Pemerintah, Bitung Dominasi Industri Pengolahan Ikan Indonesia,2018, https://jpp.go.id/ekonomi/kelautan/316890-bitung-dominasi-industri-pengolahan-ikanindonesia, diakses: 16/72021.

[5] Jasmayanti, 2019, Pengantar Pariwisata, Grasindo, Jakarta.

[6] Y. Yudhanto dan A. Wijayanto,.., 2017, Mudah Membuat dan Berbisnis Aplikasi Android dengan Android Studio, PT Elex Media Komputindo, Jakarta.

[7] Wira Shilviana Hanum dan Aries Saifudin. 2019. Rancang Bangun Aplikasi Panduan Pariwisata Di Kabupaten Banyuwangi Mobile Berbasis Android. Jurnal Teknologi Sistem Informasi dan Aplikasi, No.2, Vol.2, 59-65.

[8] Roger Presman, 2010, Sofware Engineering a practioner's Approach, Seventh Edition. Singapore a: McGraw Hill Internasional Edition.

[9] Mohamad Natsir, 2019, Aplikasi Sistem Informasi Pariwisata Tourism Pada DKI Jakarta Bermasis Android, JURNAL PETIR, No. 1, Vol. 12, 18-26.

[10] Aulia Rahmat Ramadhani , Rizky Sandy Syabana, Ati Zaidiah. 2020, Desain Aplikasi Pariwisata Untuk Menarik Pengunjung Monas Berbasis Android, Seminar Nasional Mahasiswa Ilmu Komputer dan Aplikasinya (SENAMIKA) Jakarta-Indonesia, 425-431. 